\title{
Improved Techniques for in Vitro Propagation and Germplasm Storage of Papaya
}

\author{
Roderick A. Drew \\ Redlands Research Station, P.O. Box 327, Cleveland, Queensland 4163, \\ Australia
}

Additional index words. papaw, Carica papaya, fructose, tissue culture, micropropagation

\begin{abstract}
A multiplication technique based on subculture of nodal sections from apically dominant shoots is described for papaya (Carica papaya L.). Best multiplication rates were obtained when single-node papaya sections were cultured on a modified De Fossard medium containing $0.5 \mu$ о both BAP and NAA. Shoots that developed from axillary buds were dissected and cultured for 3 days on rooting medium containing 10 $\mu \mathrm{M}$ IBA and subsequently transferred to hormone-free Drew-Smith (DS) medium. Explant growth rate was significantly reduced by substitution of $1 \%$ fructose for $2 \%$ sucrose in the medium. However, after 12 months of incubation at $25 \mathrm{C}$ without subculture, $100 \%$ of shoots on medium containing fructose were recovered when nodal sections were subcultured and grown using the above techniques. Consequent advantages are proposed for germplasm storage in lieu of low-temperature incubation. These techniques may have application to other species. Chemical names used: $\mathrm{N}^{6}$-benzylaminopurine (BAP), I $H$-naphthaleneacetic acid (NAA), $1 H$-indole-3-butyric acid (IBA).
\end{abstract}

Protocols that have been developed for in vitro propagation of plant species can be divided into three systems. System 1 is based on callus culture followed by organogenesis or embryogenesis, system 2 comprises proliferation of axillary buds and/or adventitious buds through repeated subculture on multiplication media containing cytokinin, and in system 3 microcuttings from axillary buds of apically dominant shoots are grown on hormone-free or low-cytokinin media.

Published techniques for in vitro multiplication of papaya have used either system 1 (Arora and Singh, 1978; Chen et al., 1987; De Bruijne et al., 1974; Jordan et al., 1983) or system 2 (Litz and Conover, 1977; Monda1 et al., 1990; Rajeevan and Pandey, 1986; Reuveni et al., 1990). System 1 permits rapid multiplication but is prone to production of genetic off-types (Larkin and Scowcroft 1981). The System 2 is commonly used in

Received for publication 12 Nov. 1991. Accepted for publication 13 Apr. 1992. This research was supported in part by the Horticultural Research and Development Corporation and the Committee of Direction of Fruit Marketing. The cost of publishing this paper was defrayed in part by the payment of page charges. Under postal regulations, this paper therefore must be hereby marked $a d$ vertisement solely to indicate this fact. commercial practice as it represents a compromise between high multiplication rates and genetic stability; however, it has inherent disadvantages. First, many species are difficult to root after repeated subculture on cytokinin (DeFossard, 1977). Second, resultant plants may be abnormally bushy, and reversal of form to apically dominant shoots can be difficult to achieve (DeFossard, 1977). In papaya cultures, gibberellins have been used to restore apical dominance (Mondal et al., 1990; Reuveni et al., 1990). Third, after repeated subculture of papaya, cytokinin toxicity may cause a reduction in proliferation rates (Drew, 1988), and in some cases, death of cultures (Litz, 1984; Rajeevan and Pandey, 1986). Finally, high BAP levels have been associated with production of off-types in other species (Smith and Drew, 1990).

This paper describes a multiplication technique for papaya based on system 3, i.e., subculture of nodal segments from apically dominant plants. Resultant proliferation rates were higher than those previously recorded for papaya (Miller and Drew, 1990). This paper also documents the reduced growth of papaya cultures, when, at various stages during three multiplication cycles, $1 \%$ fructose was substituted for $2 \%$ sucrose in growth media, and proposes advantages for germplasm storage.
Papaya shoot cultures were established from juvenile and adult tissue using techniques described by Drew (1988). Clone 1 was derived from a female seedling of 'Hybrid 14', a line obtained from a breeding program at Rockhampton (lat. $23.5^{\circ} \mathrm{S}$ ) in central Queensland, Australia. Clone 2 was established from adult tissue of 'OE', a highyielding female line developed in southeastern Queensland (lat. 26.5 $\mathrm{S}$ ). Clone 1 was used in multiplication experiments and clone 2 in germplasm storage experiments.

The basal multiplication medium used in these experiments was DS (Drew and Smith, 1986), which was a modified De Fossard et al. (1974) medium containing high concentrations of minerals and growth factors. Rooting medium (RM) contained intermediate concentrations of minerals and growth factors (DeFossard et al., 1974) plus $10 \mu \mathrm{M}$ IBA. Media contained 2\% sucrose unless otherwise specified. The $\mathrm{pH}$ of all media was adjusted to 5.8 with $0.1 \mathrm{M} \mathrm{KOH}$ before adding $0.8 \%$ Difco Bacto-agar and autoclaving at $121 \mathrm{C}$ for $1.5 \mathrm{~min}$. Cultures were incubated at $25 \pm 1 \mathrm{C}$ with cool-white fluorescent tubes that provided a $16-\mathrm{h}$ photoperiod and a photosynthetic photon flux of $60 \mu \mathrm{mol} \cdot \mathrm{m}^{-2} \cdot \mathrm{s}^{-1}$.

Papaya multiplication. Two experiments were performed to test the effects of several factors on micropropagation efficiency of papaya. In the first experiment, treatment 1 was the best of those described by Miller and

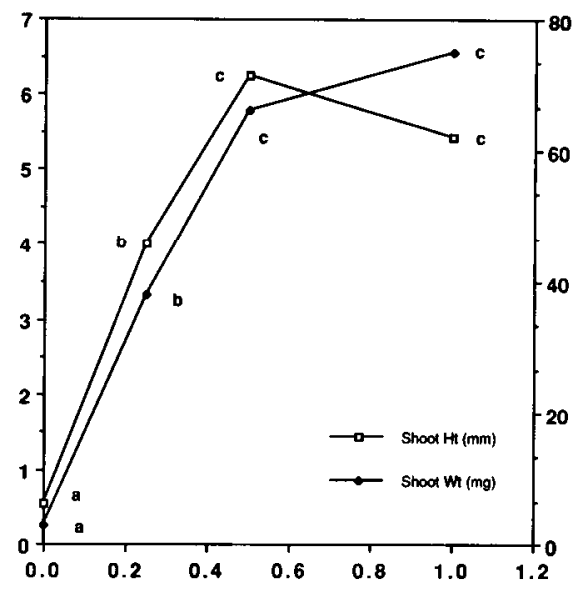

Fig. 1. Effects of BAP and NAA concentrations in DS medium (Drew and Smith, 1986) on growth of shoots from single-node papaya sections in terms of shoot height and weight. Results are means of 30 replicates. Mean separation at $P<0.01$, as determined by analysis of variance, followed by pairwise significant difference testing using the protected LSD. 


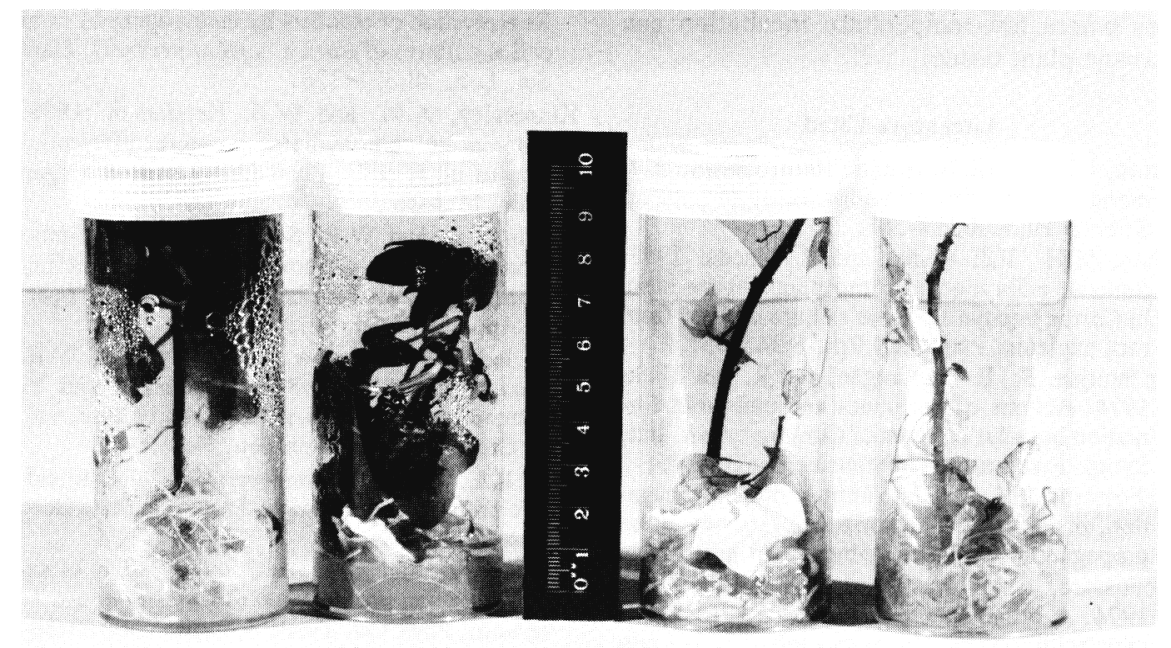

Fig. 2. Effects of $1 \%$ fructose (left) and $2 \%$ sucrose (right) on growth of papaya plantlets after 4 months without subculture on hormone-free DS medium (Drew and Smith, 1986).

Table 1. Effect of $2 \%$ sucrose and $1 \%$ fructose on papaya plants during an in vitro multiplication cycle (MC) after two previous MCs on fructose or sucrose. $\mathrm{MC}=$ single-node sections on DS plus $0.5 \mu \mathrm{M}$ of both BAP and NAA for 28 days; dissected shoots on RM plus $10 \mu \mathrm{M} \mathrm{IBA}$ for 3 days, then DS for 28 days. Data are means of 50 replicates.

\begin{tabular}{|c|c|c|c|c|}
\hline $\begin{array}{l}\text { Sugar in MC } 1 \& 2 \\
\text { Sugar in MC } 3\end{array}$ & $\begin{array}{l}\text { Sucrose } \\
\text { Sucrose }\end{array}$ & $\begin{array}{l}\text { Sucrose } \\
\text { Fructose }\end{array}$ & $\begin{array}{l}\text { Fructose } \\
\text { Sucrose }\end{array}$ & $\begin{array}{l}\text { Fructose } \\
\text { Fructose }\end{array}$ \\
\hline $\begin{array}{l}\text { Mean shoot ht }(\mathrm{cm}) \\
\text { Mean node count }\end{array}$ & $\begin{array}{c}2.8 \mathrm{a} \\
10.92 \mathrm{a}\end{array}$ & $\begin{array}{l}1.51 \mathrm{~b} \\
9.96 \mathrm{~b}\end{array}$ & $\begin{array}{l}1.81 \mathrm{~b} \\
9.06 \mathrm{c}\end{array}$ & $\begin{array}{l}0.87 \mathrm{c} \\
8.51 \mathrm{c}\end{array}$ \\
\hline Mean internode & & & & \\
\hline $\begin{array}{l}\text { length }(\mathrm{cm}) \\
\text { Final rooting }(\%)\end{array}$ & $100^{0.26 \mathrm{a}}$ & $\begin{array}{l}0.15 \mathrm{~b} \\
96\end{array}$ & $\begin{array}{l}0.20 \mathrm{c} \\
92\end{array}$ & $\begin{array}{l}0.10 \mathrm{~d} \\
82^{-1}\end{array}$ \\
\hline $\begin{array}{l}\text { Time to final } \\
\text { rooting }(\%)(\text { days })^{\mathbf{z}}\end{array}$ & 15 & 16 & 30 & 31 \\
\hline $\begin{array}{l}\text { Time to } 50 \% \\
\text { rooting (days) }\end{array}$ & 8 & 13 & 14 & 15 \\
\hline
\end{tabular}

${ }^{\mathrm{z}}$ Time in days after transfer to rooting medium. Mean separation at $P<0.01$ (across rows) as determined by analyses of variance followed by pairwise significant difference testing using the protected LSD test.

Drew (1990). Rooted shoots $4 \mathrm{~cm}$ high, with apices removed and roots trimmed, were placed on DS medium containing $2.0 \mu \mathrm{M}$ BAP and $0.5 \mu \mathrm{M}$ NAA. After 4 weeks, axillary shoots were harvested and placed on RM for 3 weeks before transfer to hormonefree DS for 3 weeks. Ten plants produced 67 axillary shoots of which $61 \%$ rooted, giving a multiplication rate of $4.1: 1$ in 10 weeks. In treatments 2 and 3, 4-cm-high rooted shoots were dissected midway between the nodes into double-node or single-node sections, respectively, and cultured for 2 weeks on DS medium containing $1 \mu \mathrm{M}$ of both BAP and NAA, followed by 2 weeks on hormone-free DS medium. Shoots that had developed were then excised from the nodal sections, cultured on RM for 3 weeks, and then on hormone-free DS medium for 3 weeks. In treatment 2, 50 double nodes from 10 plants produced 90 shoots, a rooting percentage of $68 \%$ and a multiplication rate of $6.1: 1$ in 10 weeks. In treatment 3, 100 single nodes from 10 plants yielded 92 shoots, a rooting percentage of $88 \%$ and a multiplication rate of $8.1: 1$ in 10 weeks. Whereas treatments 1 and 2 produced shoots of variable quality and height, single nodes (treatment 3) produced
$(0.5 \mu \mathrm{M})$ (Fig. 1) eliminated the need for this transfer. Resultant shoots were then excised and cultured on RM medium (minus riboflavin) for 3 days before growth on hormone-free DS medium for 4 weeks more.

This system was better than that described previously for papaya (Miller and Drew, 1990). It increased the number of shoots $>5$ $\mathrm{mm}$ in height that can be obtained in 4 weeks, thereby producing higher multiplication rates. Five millimeters was shown to be the critical length of papaya shoots for root initiation (Miller and Drew, 1990), and largely determined rooting percentages in Expt. 1.

This multiplication system has four main advantages. First, the use of single apically dominant shoots at all stages avoids problems associated with form reversal before rooting, and it produces consistently high rooting percentages $(>90 \%)$.

Second, by using only 3 days of exposure to IBA, shoot damage is avoided, rooting is enhanced, and the length of the multiplication cycle reduced. Although IBA is essential for root initiation in papaya (Drew, 1987), prolonged exposure to IBA retards root and shoot growth (Drew, 1991). Three days of exposure to IBA has been shown to be optimal for rooting of papaya in terms of rooting percentage and time to $50 \%$ rooting (Drew, 1991). Inhibitory effects of IBA on root growth have been reported in other species, both on cuttings (Went, 1939) and in vitro (James, 1983).

Third, this system is not prone to shoot damage or reduced proliferation rates caused by BAP. Excess BAP has been shown to inhibit shoot growth and reduce proliferation rates with papaya (Drew, 1988). BAP should be used in low concentrations and only to initiate growth of dormant buds. Subsequent shoot growth is better on hormone-free medium (Drew, 1988).

Finally, because shoots are produced only from axillary buds and exposure to BAP is reduced, off-type production should be minimized. Five hundred plants of clone 2, multiplied using this technique, have been planted in coastal Queensland and grown through to fruiting. Four dwarf off-types (a frequency of $0.8 \%$ ) have occurred and all originated from the same bud explants.

This multiplication technique has also been used to propagate neem (Azadirachta indica A. Juss) and coffee (Coffea arabica L.) clones (Drew, 1991) and should be applicable to other species exhibiting strong apical dominance.

Effects of sugars on shoot growth. Ten plants were subcultured on media containing either $2 \%$ sucrose or $1 \%$ fructose for two complete multiplication cycles (MC), as described above. In the third MC, cultures were either maintained on the sugar of the previous two MCs or changed to the alternate sugar. At the end of the third MC, plants grown on medium containing fructose exhibited reduced shoot height, internode length, and final rooting percentage and increased time to root (Table 1). Growth during the third MC was affected by the sugar treatment of the first two MC's (Table 1). This result 
emphasizes the importance of monitoring growth for several subcultures when determining the effects of sugars and is consistent with the results of Kinnersley and Henderson (1988).

After an additional 4 months without transfer, plants that were cultured on media containing fructose for three MCs were still green and were approaching senescence (Fig. 2 ), compared with plants on sucrose for three MCs, which had ceased growing and had abscissed all leaves after 2 months. After 4 months however, the plants on sucrose, although dormant, still had healthy axillary buds (Fig. 2).

After 12 months, one third of the plants on sucrose medium had died. Three-fourth of nodal shoots from surviving plants were recovered after subculture, representing a $50 \%$ recovery rate for this treatment. However, $100 \%$ of buds were recovered from nodal segments of dormant plants on the fructose treatment after 12 months without subculture. This result contrasts with previous in vitro systems where it was essential to maintain active growth by subculturing papayas every 3 to 4 weeks (Drew, 1988; Miller and Drew, 1990). Fructose at $1 \%$ and sucrose at $2 \%$ were the optimum concentrations of these sugars when shoot growth from papaya nodal sections was compared on autoclaved media containing various sugars within the concentration range of $0 \%$ to $4 \%$ (Drew, 1992). Fructose has been shown to reduce glycolysis when added to tissue culture media (Redei, 1973a, 1973b). More work is required to determine whether reduced growth rates observed in the current experiment are due to the sugar or its concentration. Further studies on the effects of these factors on the growth of apically dominant plantlets in vitro may lead to the development of a technique for germplasm storage of other tropical spe- cies where low-temperature incubation can damage plant tissue.

\section{Literature Cited}

Arora, I.K. and R.N. Singh. 1978. Growth hormones and in vitro callus formation of papaya. Scientia Hort. 8:357-361.

Chen, M.H., P.J. Wang, and E. Maeda. 1987. Somatic embryogenesis and plant regeneration in Carica papaya L. tissue culture derived from root explants. Plant Cell Rpt. 6:348-351.

De Bruijne, E., E. De Langhe, and R. van Rijck. 1974. Actions of hormones and embryoid formation in callus cultures of Carica papaya. Intl. Symp. Fytofarmacia. Fytiatrie. 26:637-645.

DeFosaard; R.A. 1977. Tissue culture propagation. o. 1-14. In: The horizons of tissue culture propagation. Univ. of Sydney, Australia.

DeFossard, R.A., A. Myint, and E.C.M. Lee. 1974. A broad spectrum tissue culture experiment with tobacco (Nicotiana tabacum L.) pith tissue callus. Physiol. Plant. 31:125-130.

Drew, R.A. 1987. The effects of medium composition and cultural conditions on in vitro root initiation and growth of papaya (Carica papaya L.). J. Hort. Sci. 62:551-556.

Drew, R.A. 1988. Rapid clonal propagation of papaya in vitro from mature field grown trees. HortScience 23:609-611.

Drew, R.A. 1991. Optimizing root initiation by controlling exposure to auxin. Intl. Plant Propagators' Soc. Combined Proc. 41:70-75.

Drew, R.A. 1992. Factors affecting growth responses to fructose and other sugars, p. 65-82. In: Tissue culture and field evaluation of papaya (Carica papaya L.). PhD Diss., Murdoch Univ., Murdoch, Western Australia.

Drew, R.A. and N.G. Smith. 1986. Growth of apical and lateral buds of papaw (Carica papaya L.) as affected by nutritional and hormonal factors. J. Hort. Sci. 61:535-543.

James, D.J. 1983. Adventitious roof formation in vitro in apple rootstocks (Malus pumila) I. Factors affecting the length 'of the -auxin-Sensitive ohase in M.9. Physiol. Plant. 57:149-151.

Jordan, M., I. Cortes, and G. Montenegro. 1983.
Regeneration of plantlets by embryogenesis from callus cultures of Carica candamarcensis. Plant Sci. Lett. 28:321-326.

Kinnersley, A.M. and W.E. Henderson. 1988. Alternative carbohydrates promote differentiation of plant cells. Plant Cell Tissue \& Organ Cult. 15:3-16.

Larkin, P.J. and W.R. Scowcroft. 1981. Somaclonal variation-A novel source of variability from cell culture for plant improvement. Theor. \& Applied Genet. 60:197-214.

Litz, R.E. 1984. Papaya, p. 349-368. In: W.R. Sharp, D.A. Evans, P.V. Ammirato, and Y. Yamada (eds.). Hdbk of plant cell culture, vol. 2. Crop species. Macmillan, New York.

Litz, R.E. and R.A. Conover. 1977. Tissue culture. propagation of papaya. Proc. PIa. State Hort. Soc. 90:245-246.

Miller, R.M. and R.A. Drew. 1990. Effect of explant type on proliferation of Carica papaya $\mathrm{L}$. in vitro. Plant Cell Tisse \& Organ Cult. 21:3944.

Mondal, M., S. Gupta, and B.B. Mukherjee. 1990. In vitro propagation of shoot buds of Carcia papaya I. (Caricaceae) var. Honey Dew. Plant Cell Rpt. 8:609-612.

Rajeevan, MS. and R.M. Pandey. (1986). Lateral bud culture of papaya (Carica papaya $\mathrm{L}$.) for clonal propagation. Plant Cell Tissue \& Organ Cult. 6:181-188

Redei, G.P. 1973a. Effects of the degradation products of fructose on the glycolytic pathway. Z. Pflanzenphysiol. 70:97-106.

Redei, G.P. 1973b. Effects of autoclaved fructose media on metabolites in three cruciferous plants. Z. Pflanzenphysiol. 70:107-114.

Reuveni, O., D.R. Shlesinger, and U. Lavi. 1990. In vitro clonal propagation of dioecious Carica papaya. Plant Cell Tissue \& Organ Cult. 20:4146.

Smith, M.K. and R.A. Drew. 1990. Current applications of tissue culture in plant propagation and improvement. Austral. J. Plant Physiol. 17:267:289.

Went, F.W. 1939. The dual effect of auxin on root formation. Amer. J. Bot. 26:24-29. 